Article

\title{
Activated Carbon Supported Mo-Ti-N Binary Transition Metal Nitride as Catalyst for Acetylene Hydrochlorination
}

\author{
Hui Dai ${ }^{1}$, Mingyuan Zhu ${ }^{2}$, Haiyang Zhang ${ }^{2}$, Feng Yu ${ }^{2}$ (D), Chao Wang ${ }^{2}$ and Bin Dai ${ }^{2, *}$ \\ 1 School of Chemical Engineering \& Technology, Tianjin University, Tianjin 300072, China; ddwr1314@163.com \\ 2 Key Laboratory for Green Processing of Chemical Engineering of Xinjiang Bingtuan, School of Chemistry \\ and Chemical Engineering, Shihezi University, Shihezi 832003, China; zhuminyuan@shzu.edu.cn (M.Z.); \\ zhy198722@163.com (H.Z.); yufeng05@mail.ipc.ac.cn (F.Y.); 18290730636@163.com (C.W.) \\ * Correspondence: db_tea@shzu.edu.cn; Tel.: +86-993-205-7277
}

Academic Editor: Elena Pastor

Received: 5 May 2017; Accepted: 27 June 2017; Published: 30 June 2017

\begin{abstract}
Recently, many scientists have focused on the development of green industrial technology. However, the process of synthesizing vinyl chloride faces the problem of $\mathrm{Hg}$ pollution. Via a novel approach, we used two elements Mo and Ti to prepare an inexpensive and green binary transition metal nitride (BTMN) as the active ingredient in a catalyst with nano-sized particles and an excellent degree of activation, which was supported on activated carbon. When the Mo/Ti mole ratio was $3: 1$, the conversion of acetylene reached $89 \%$ and the selectivity exceeded $98.5 \%$. The doping of Ti in Mo-based catalysts reduced the capacity of adsorption for acetylene and also increased the adsorption of hydrogen chloride. Most importantly, the performance of the BTMN excelled those of the individual transition metal nitrides, due to the synergistic activity between Mo and Ti. This will expand the new epoch of the employment of transition metal nitrides as catalysts in the hydrochlorination of acetylene reaction.
\end{abstract}

Keywords: binary transition metal nitride; acetylene hydrochlorination

\section{Introduction}

Polyvinylchloride (PVC) has excited much attention owing to its high application value, low price, and comparatively simple preparation process. However, its manufacturing process still faces an environmental issue, namely, in the synthesis of vinyl chloride monomer (VCM), which is the monomer of PVC, Hg used as the catalyst easily accumulates, which simultaneously brings about hazards to the environment. This problem has been the subject of heated discussion among scholars in recent years [1,2]. Some metals have already been found to replace $\mathrm{Hg}$ as a catalyst for the preparation of VCM. Novel catalysts with high performance and stability are required, furthermore, they must be non-polluting and harmless. The search for catalysts tends to focus on metals that are active, but expensive and rare in the earth, to which the practical development of catalysts, such as Au-based [3-7] and Ru-based [8,9] catalysts, has been confined. Many scientists are concentrating on a reduction in the required load of noble metal while maintaining the same degree of activation. The addition of a second base metal, such as La [4], Co [5], Ni [10], Cu [11], and Cs [12], can modulate the electronic properties, which prevents the reduction of the +3 valence state of $\mathrm{Au}$ to a low valence, and more over promotes the whole activity. However, the problems that still face the use of $\mathrm{Au}$ as the main activated catalyst are that its cost is too high and it is hard to industrialize. Apart from that, the addition of non-metallic elements, such as P [13], N [14,15], B [16], etc., has been carried out. Whether these were added to the support or the active ingredient, the enhancement in performance 
due to these hetero atoms can transport extra electrons to the active site. Bao et al. reported a nano composite $\mathrm{N}$-doped carbon catalyst supported by $\mathrm{SiC}$, which exhibited an excellent degree of activation, with an analysis of its reaction mechanism, in which carbon atoms bonded to pyrrolic-N play a very important role [17]. Zhao et al. (2016), who added $\mathrm{CuCl}_{2}$ to g- $\mathrm{C}_{3} \mathrm{~N}_{4}$ /activated carbon (AC) as a catalyst for this reaction, increased the content of pyrrolic- $\mathrm{N}$ and improved the adsorption performance for the reacting gases [18]. It was demonstrated in a number of studies that the addition of nitrogen sources will help improve activation, besides, connected with base metals, which have become the focus of study.

In the last few years, scientists have been eager to find a substitute for noble metals. Fortunately, new materials, namely, transition metal nitrides (TMNs), have emerged. Many studies have focused on the analogies between the catalytic efficacy of TMNs and that of noble metals [19]. With lower costs than noble metals, thermal stability, and high melting points, TMNs also possess high chemical stability and most importantly, have excellent catalytic properties in many reactions, which are attributed to the fact that they exhibit platinum-like electronic structures. When the p-orbital of a heteroatom such as $\mathrm{N}, \mathrm{C}$, or $\mathrm{S}$ overlaps with a d-orbital of a transition metal, this can lead to an expansion in the metal lattice that generates a new d-band [20]. This combination gives rise to a higher density of states near the Fermi level that approach the d-band of $\mathrm{Pt}[21,22]$, and is based on two main forms that participate in the reaction. The first is as a carrier: Pan et al. [23] synthesized TiN nanotubes with a mesoporous structure, on which supported $\mathrm{Pt}$ was better than $\mathrm{Pt} / \mathrm{C}$ in both activity and durability in the oxygen reduction reaction. There was a strong synergistic interaction between $\mathrm{Pt}$ and the TiN nanotubes. TMNs as supports for loading Pt or Pd as an electrocatalyst in direct methanol fuel cells exhibited high degrees of activation, even beyond that of $\mathrm{Pt} / \mathrm{C}$ catalysts. Besides, a large surface area and a porous structure are also aims in the synthesis of binary transition metal nitrides (BTMNs). A one-pot solvothermal process has been used to prepare $\mathrm{Ti}_{0.8} \mathrm{Mo}_{0.2} \mathrm{~N}$ hybrid support, of which the surface area can reach $148 \mathrm{~m}^{2} \mathrm{~g}^{-1}$, and which also contains a large amount of mesopores. When used as a support and decorated with Pt nanoparticles it exhibited excellent catalytic durability, which even exceeded that of a Pt/C catalyst in the methanol oxidation reaction [24]. Later, it was found that TMNs can be directly used as an active constituent that participates in the reaction. Using hydrothermal treatment, it was easy to fabricate hybrid 2D-0D graphene-VN quantum dots, which were used for lithium and sodium storage and of which the unique multiporous structure can prevent the aggregation of $\mathrm{VN}$ particles during the cycling process and the continuous graphene backbone leads to the fast diffusion of lithium and electrons [25]. Subsequently, BTMNs also became involved, and transition metals ( $\mathrm{Fe}, \mathrm{Co}$, and $\mathrm{Ni}$ ) were doped with Ti using an $\mathrm{NH}_{3}$ temperature-programmed method to obtain three different BTMN nanoparticles for the oxygen reduction reaction [26]. Under acidic conditions, $\mathrm{Ti}_{0.95} \mathrm{Ni}_{0.05} \mathrm{~N}$ exhibits an excellent degree of activation, because doping with the transition metal can weaken the bonds between the Ti and $\mathrm{O}$ atoms. The four-layered stacking structure $\mathrm{Co}_{0.6} \mathrm{Mo}_{1.4} \mathrm{~N}_{2}$ was employed under acidic conditions for the hydrogen evolution reaction; this layered structure allows the $3 \mathrm{~d}$ transition metal to tune the electronic states of Mo at the surface of the catalyst without disrupting its catalytic activity [27]. In addition to these reactions, the hydrogenation of CO [28], production of hydrogen by decomposition of ammonia [29], and epoxidation of alkenes [30], etc., all proceeded with excellent activity.

BTMNs are generally promising for many catalytic applications, as they have high corrosion resistance. However, studies regarding the fabrication of BTMNs catalysts for employment in the hydrochlorination of acetylene, which would be an effective way of carrying out this reaction, are rare. We were therefore motivated to investigate the catalytic activity for the acetylene hydrochlorination of molybdenum and titanium BTMNs loaded on the classic support AC, of which the activity has not previously been reported. 


\section{Experimental}

\subsection{Materials}

$\mathrm{NH}_{3}$ (gas, $99.999 \%$ ), $\mathrm{N}_{2}$ (gas, $\left.99.99 \%\right), \mathrm{C}_{2} \mathrm{H}_{2}$ (gas, $\geq 98 \%$ ) and $\mathrm{HCl}$ (gas, $\geq 99 \%$ ), $\mathrm{MoCl}_{5}(99.6 \%$ metal basis, purchase from Aladdin, Shanghai, China), $\mathrm{TiCl}_{4}$ (Tianjin Guangfu Chemical reagent, Tianjin, China) and AC (20-40 mesh, coconut shell activated carbon).

\subsection{Preparation of Catalysts}

The Mo-Ti-N catalysts were synthesized by a hydrothermal method using a tandem ammonia calcination process [24]. Different molar proportions of $\mathrm{MoCl}_{5}$ and $\mathrm{TiCl}_{4}$ were dissolved in deionized water (more details are given in Table 1), and $5 \mathrm{~g}$ AC was added to the aqueous solution at room temperature (RT; $28^{\circ} \mathrm{C}$ ) and kept under continuous stirring for one day. Next, the mixture was poured into a Teflon-sealed autoclave and heated at $150^{\circ} \mathrm{C}$ for $3 \mathrm{~h}$. When it had cooled down to RT, the mixture was filtered and washed with deionized water. The product was dried in an oven at $80^{\circ} \mathrm{C}$ and afterward was subjected to $\mathrm{NH}_{3}(\mathrm{~g})$ calcination treatment, in which the flow rate was $100 \mathrm{~mL} / \mathrm{min}$ and the heating rate was $5{ }^{\circ} \mathrm{C} / \mathrm{min}$ from $\mathrm{RT}$ to $750^{\circ} \mathrm{C}$, at which temperature the product was maintained for $2 \mathrm{~h}$ then cooled down to RT to obtain the ternary metal nitride. TiN/AC and $\mathrm{Mo}_{2} \mathrm{~N} / \mathrm{AC}$ were prepared using the same processes, only without using the other metal (Mo or Ti, respectively).

Table 1. Detailed synthetic ratio and the physicochemical properties.

\begin{tabular}{cccccccc}
\hline \multirow{2}{*}{ Samples } & \multirow{2}{*}{ Mole Ratio } & \multicolumn{2}{c}{$\boldsymbol{D}(\mathbf{n m})$} & \multicolumn{2}{c}{$S_{\text {BET }}\left(\mathbf{m}^{\mathbf{2}} \mathbf{g}^{-\mathbf{1}}\right)$} & \multicolumn{2}{c}{$V_{\text {tot }}\left(\mathbf{c m}^{\mathbf{3}} \mathbf{g}^{-\mathbf{1}}\right)$} \\
\cline { 3 - 7 } & & Fresh & Used & Fresh & Used & Fresh & Used \\
\hline $\mathrm{AC}$ & - & 2.2 & 2.1 & 948 & 915 & 0.52 & 0.48 \\
$\mathrm{Mo}_{2} \mathrm{~N} / \mathrm{AC}$ & - & 2.1 & 1.9 & 811 & 40 & 0.43 & 0.19 \\
$\mathrm{TiN} / \mathrm{AC}$ & - & 2.2 & 2.2 & 889 & 881 & 0.49 & 0.47 \\
$\mathrm{Mo}_{1} \mathrm{Ti}_{1} \mathrm{~N} / \mathrm{AC}$ & $\mathrm{Mo:Ti}=1: 1$ & 2.2 & 2.6 & 649 & 30 & 0.36 & 0.19 \\
$\mathrm{Mo}_{2} \mathrm{Ti}_{1} \mathrm{~N} / \mathrm{AC}$ & $\mathrm{Mo:Ti}=2: 1$ & 2.1 & 2.8 & 680 & 33 & 0.36 & 0.23 \\
$\mathrm{Mo}_{3} \mathrm{Ti}_{1} \mathrm{~N} / \mathrm{AC}$ & $\mathrm{Mo:Ti}=3: 1$ & 2.2 & 2.7 & 772 & 32 & 0.42 & 0.20 \\
$\mathrm{Mo}_{4} \mathrm{Ti}_{1} \mathrm{~N} / \mathrm{AC}$ & $\mathrm{Mo:Ti}=4: 1$ & 2.2 & 2.6 & 785 & 27 & 0.43 & 0.18 \\
\hline
\end{tabular}

\subsection{Characterization Techniques}

X-ray diffraction (XRD) with a Bruker D8 diffractometer was used to determine the structures of the catalysts. A Micromeritics ASAP 2020 instrument was used for the analysis of surface areas and pore size distributions. A Kratos AXIS Ultra DLD spectrometer was employed for X-ray photoelectron spectroscopy (XPS) to analyze the electronic states and proportions of atoms on the surfaces of samples. An AutoChem 2720 instrument (Micromeritics Instrument Corporation, Norcross, GA, USA) was used to conduct temperature-programmed reduction and desorption. An SDT Q600 analyzer (TA Instruments, New Castle, DE, USA) was used for the thermogravimetric analysis of the samples. The Ti and Mo contents of the samples were determined by an inductively coupled plasma-optical emission spectrometer (ICP-OES) (Agilent 725, Santa Clara, CA, USA). Elemental analysis (EA) was used to test the $\mathrm{N}$ content in the catalysts using a vario EL cube analyzer (Elementar, Langenselbold, Germany).

\subsection{Experimental Measurements}

A fixed-bed flow micro reactor was used to test the catalytic performance at atmospheric pressure. To eliminate the harmful effects of air, the reactor was swept with nitrogen for one hour before the reaction. Besides, hydrogen chloride gas $\left(25 \mathrm{~mL} \mathrm{~min}^{-1}\right)$ was allowed to pass through the reactor until the reaction temperature of $180^{\circ} \mathrm{C}$ was reached for another one hour, with the aim of activating the catalyst by this motion. After that, the two reagents were fed into the reactor at a gas hourly space velocity (GHSV) of $50 \mathrm{~h}^{-1}$. The reaction products were analyzed by gas chromatography (GC-2014C). 


\subsection{Analytical Methods and Criteria}

After the reaction, the exit gas mixture in the reaction pass through the absorption bottle, which was used to absorb residual $\mathrm{HCl}$ after reaction. Other compositions of the product were injected into a Shimadzu GC-2014C for analysis.

The following equations were respectively expound the criteria of catalytic performance from two parts: acetylene conversion and VCM selectivity.

$$
\begin{gathered}
\mathrm{C}_{2} \mathrm{H}_{2} \text { conversion }=\left(\Phi_{\mathrm{A} 0}-\Phi_{\mathrm{A}}\right) / \Phi_{\mathrm{A} 0} \times 100 \% \\
\mathrm{VCM} \text { selectivity }=\Phi_{\mathrm{VC}} /\left(1-\Phi_{\mathrm{A}}\right) \times 100 \%
\end{gathered}
$$

where $\Phi_{\mathrm{A} 0}$ is representative the volume fraction of $\mathrm{C}_{2} \mathrm{H}_{2}$ before the reaction, $\Phi_{\mathrm{A}}$ is representative the volume fraction of $\mathrm{C}_{2} \mathrm{H}_{2}$ still remained in the product gas, and $\Phi_{\mathrm{VC}}$ is defined as the volume fraction of vinyl chloride after the reaction.

\section{Results and Discussion}

\subsection{Morphology of Samples}

The different XRD patterns of the BTMNs and TMNs are compared in Figure 1. The two precursors have different diffraction peaks. The TiN/AC sample does not exhibit peaks of a pure metal nitride phase, and there also exists a number of $\mathrm{TiO}_{2}$ peaks. During the calcination process many nanoparticles possibly formed with a crystalline structure of TiN, with subsequent coating of the surface by a $\mathrm{TiO}_{2}$ film in the atmosphere, and diffraction peaks of TiN are hardly found. Similar synthesis conditions are to be found for $\mathrm{Mo}_{2} \mathrm{~N} / \mathrm{AC}$, in which nanoparticles were supposedly formed; by contrast, the formation of an oxide layer was more difficult. Powder XRD studies of the BTMNs suggest that they are isostructural with $\mathrm{Mo}_{2} \mathrm{~N} / \mathrm{AC}$. As the Mo:Ti mole ratio increased in the BTMN samples, an increase in the molybdenum titanium nitride phase and a decrease in the $\mathrm{TiO}_{2}$ phase took place. When the proportion of Mo:Ti was $>3$, the impurity peaks completely disappeared. For the BTMNs, the diffraction peaks of $\mathrm{Mo}_{2} \mathrm{~N}$ were slightly shifted to smaller angles. According to the Bragg Equation [31], when the incident angle increased and the wavelength was fixed, this phenomenon implies that the inter planar spacing of $\mathrm{Mo}_{2} \mathrm{~N}$ was increased. This suggests that an atom or ion with an atomic radius larger than that of $\mathrm{Mo}$ had been inserted into the $\mathrm{Mo}_{2} \mathrm{~N}$ lattice phase; $\mathrm{Ti}(0.067 \mathrm{~nm})$ has a larger ionic radius than Mo $(0.059 \mathrm{~nm})$ [32]. Furthermore, no other element peaks were detected and also the Ti atom was suitable for this phenomenon, which suggests that a Ti atom was added in the space between the Mo and N atoms.

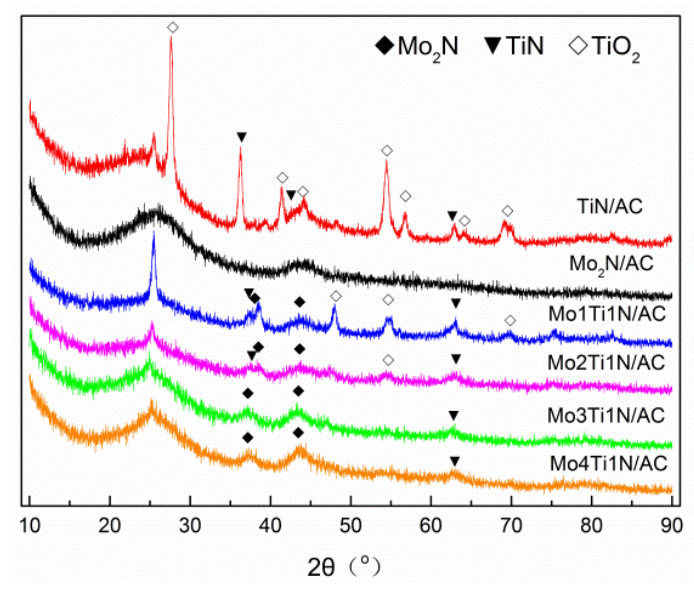

Figure 1. XRD patterns for six different catalysts. 
From Figure 1, bonding between Ti and N in the TiN/AC sample can hardly be observed; besides, $\mathrm{Mo}$, Ti, and $\mathrm{N}$ further combined with each other in the BTMNs. We used temperature-programmed desorption-mass spectrometry (TPD-MS) analysis to solve that problem according to the three different gases used for desorption, which were $\mathrm{NH}_{x}(x=1-3)(\mathrm{m} / \mathrm{e}=17), \mathrm{H}_{2} \mathrm{O}(\mathrm{m} / \mathrm{e}=18)$, and $\mathrm{N}_{2}(\mathrm{~m} / \mathrm{e}=28)$ [33], as shown in Figure 2. The former two gases always appear as a desorption peak at low temperatures. If a peak of $\mathrm{NH}_{x}$ arises, this means that an amount of $\mathrm{NH}_{x}$ groups were present on the surface of the catalysts during the calcination process. As the catalyst adsorbs water from the air, the peak of $\mathrm{H}_{2} \mathrm{O}$ would increase. Both peaks emerged for $\mathrm{Mo}_{2} \mathrm{~N} / \mathrm{AC}$ as the temperature approached $200{ }^{\circ} \mathrm{C}$. However, unlike $\mathrm{Mo}_{2} \mathrm{~N} / \mathrm{AC}$, for TiN/AC the location of these two peaks appeared beginning at $50^{\circ} \mathrm{C}$. Then, on combining the two TMNs together, in comparison with $\mathrm{Mo}_{2} \mathrm{~N} / \mathrm{AC}$ not only did the area of the water peak increase, but the peak also shifted to lower temperatures. Moreover, the shape of the $\mathrm{NH}_{x}$ peak became broader, which shows that the change in ingredients led to a change in the adsorbed surface groups on the catalysts. The peak of $\mathrm{N}_{2}$ underwent the most evident change of all. When the bond between the metal and nitride that exists in TMNs breaks, this would lead to the production of $\mathrm{N}_{2}$ in the high-temperature range [33]. A sharper peak emerged at $756{ }^{\circ} \mathrm{C}$ for $\mathrm{Mo}_{2} \mathrm{~N} / \mathrm{AC}$, which confirmed the bonding between $\mathrm{Mo}$ and $\mathrm{N}$ in the catalyst. In comparison with this, TiN/AC had two peaks at 810 and $926.8^{\circ} \mathrm{C}$, which means that two different combined forms of Ti and $\mathrm{N}$ were present. BTMNs basically displayed a combination of two peaks around 760 and $800{ }^{\circ} \mathrm{C}$, which corresponded to Mo-N and Ti-N bonds, respectively. A more obvious phenomenon was that the desorption temperature of Mo-N shifted upward; in contrast, that of Ti-N shifted downward. This indicated that the three elements underwent mutual combination in the BTMNs catalysts, not simply mechanical mixture. $\mathrm{Mo}_{4} \mathrm{Ti}_{1} \mathrm{~N} / \mathrm{AC}$ did not display two clear $\mathrm{N}_{2}$ peaks, and only a faint shoulder peak was discovered around $800{ }^{\circ} \mathrm{C}$, which resulted in the conclusion that the content of Ti was minimal. This analysis directly confirms that bonding between the metal and $\mathrm{N}$ was present in BTMNs.
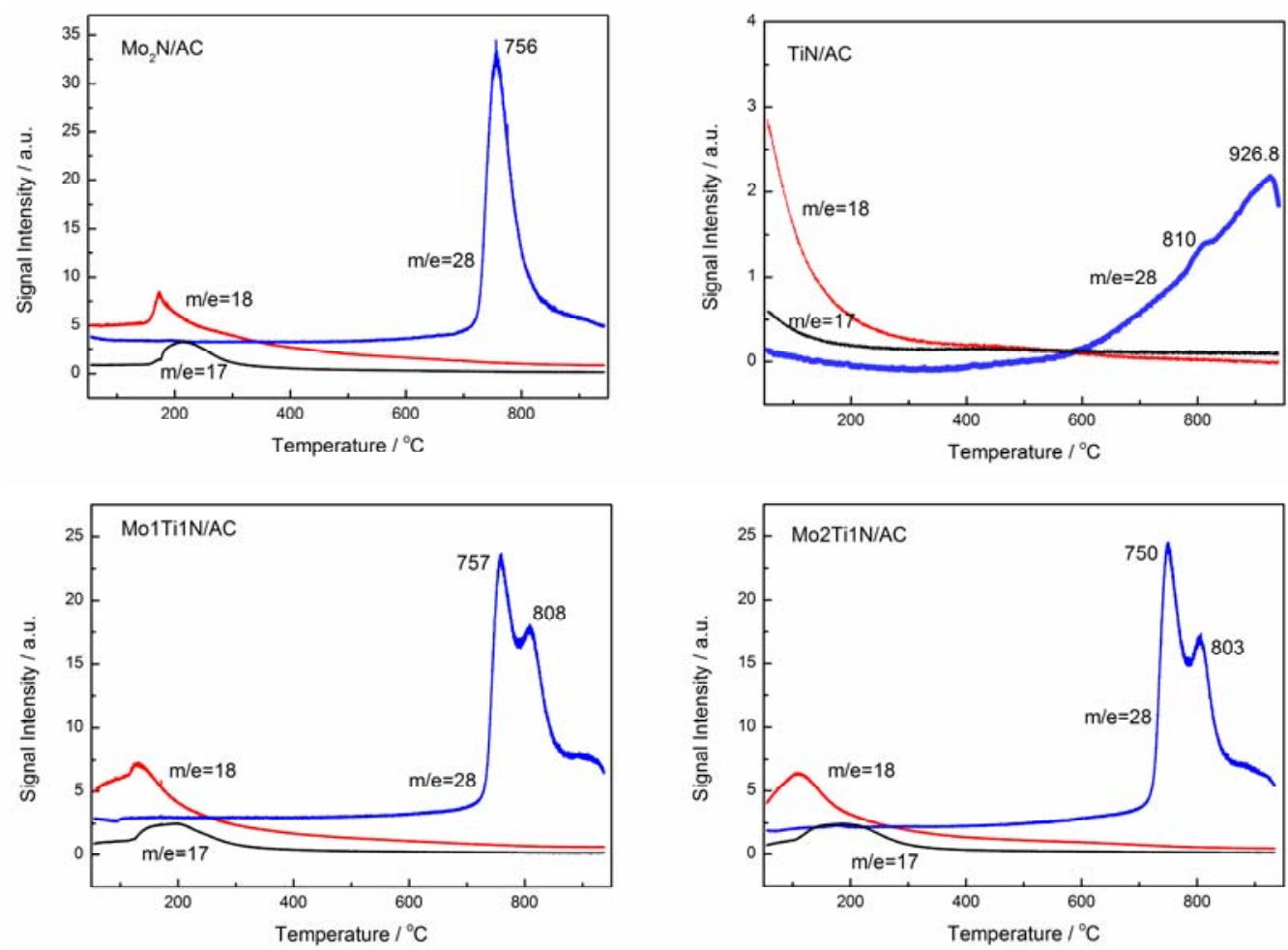

Figure 2. Cont. 

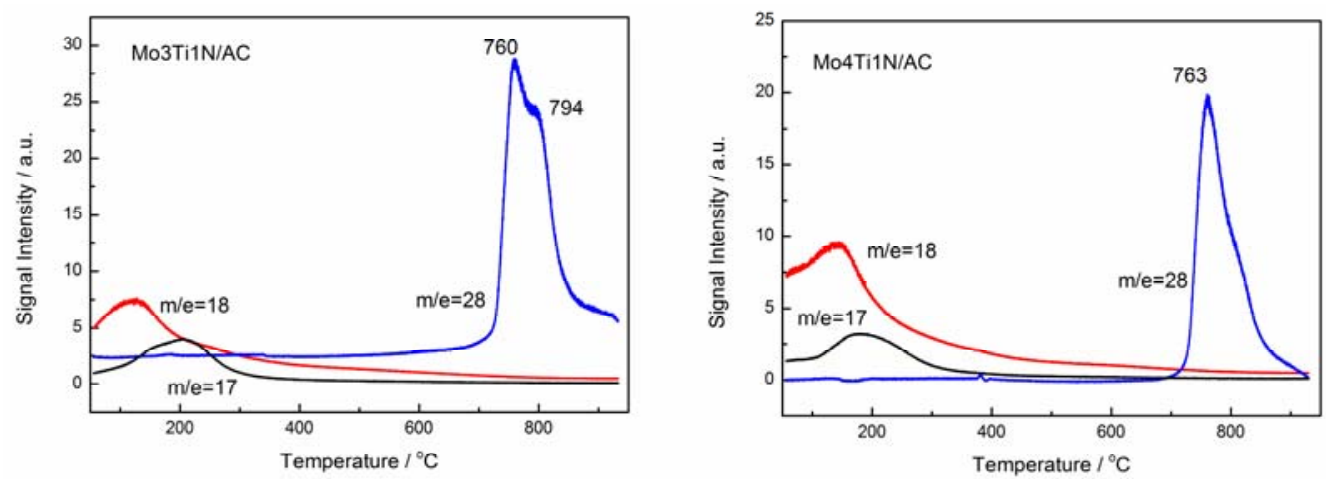

Figure 2. TPD-MS profiles of six catalysts.

\subsection{Catalytic Performance of Catalysts in Acetylene Hydrochlorination Reaction}

A comparison of the activity for the seven different samples in the acetylene hydrochlorination reaction is shown in Figure 3. AC, as supported, had lower activity that only reached 35\%, owing to its unique structure, large specific surface area, and amount of functional groups. It is obvious that TiN hardly influenced the catalytic activity, because TiN/AC had similar activity to the support. In sharp contrast, with the other TMN catalyst $\mathrm{Mo}_{2} \mathrm{~N} / \mathrm{AC}$ the conversion of acetylene rose from $58 \%$ at the start of the reaction to $74 \%$ after the reaction had proceeded for $2 \mathrm{~h}$, after which it fell slightly to $55 \%$. When the two TMNs were combined the activity and stability were both significantly improved: the trend for $\mathrm{Mo}_{1} \mathrm{Ti}_{1} \mathrm{~N} / \mathrm{AC}$ exhibited a rise from $56 \%$ to $80 \%$, whereas $\mathrm{Mo}_{2} \mathrm{Ti}_{1} \mathrm{~N} / \mathrm{AC}$ reached $85 \%$ in around $3 \mathrm{~h}$. Among these BTMNs, $\mathrm{Mo}_{3} \mathrm{Ti}_{1} \mathrm{~N} / \mathrm{AC}$ displayed excellent activity, with a conversion of acetylene about $62 \%$ at the beginning, which then increased to $89 \%$. It is clear that the stability became worse when the Mo:Ti molar ratio was 4:1, which may have been caused by the deposition of coke. The conversion of acetylene decreased in the order of $\mathrm{Mo}_{3} \mathrm{Ti}_{1} \mathrm{~N} / \mathrm{AC}>\mathrm{Mo}_{4} \mathrm{Ti}_{1} \mathrm{~N} / \mathrm{AC}>\mathrm{Mo}_{2} \mathrm{Ti}_{1} \mathrm{~N} / \mathrm{AC}>$ $\mathrm{Mo}_{1} \mathrm{Ti}_{1} \mathrm{~N} / \mathrm{AC}>\mathrm{Mo}_{2} \mathrm{~N} / \mathrm{AC}>\mathrm{TiN} / \mathrm{AC}$. The selectivity for VCM of the catalysts is shown in Figure $3 \mathrm{~b}$. The lowest selectivity was displayed by the carrier, and $\mathrm{Mo}_{2} \mathrm{~N} / \mathrm{AC}$ followed. In comparison, TiN/AC possessed high selectivity; moreover, on adding Ti to Mo-based BTMN catalysts, the selectivity was also improved and reached $98.5 \%$ in all cases. The performance of the BTMNs excelled those of the two TMNs, and we can therefore speculate that there was synergistic activity between Mo and Ti.
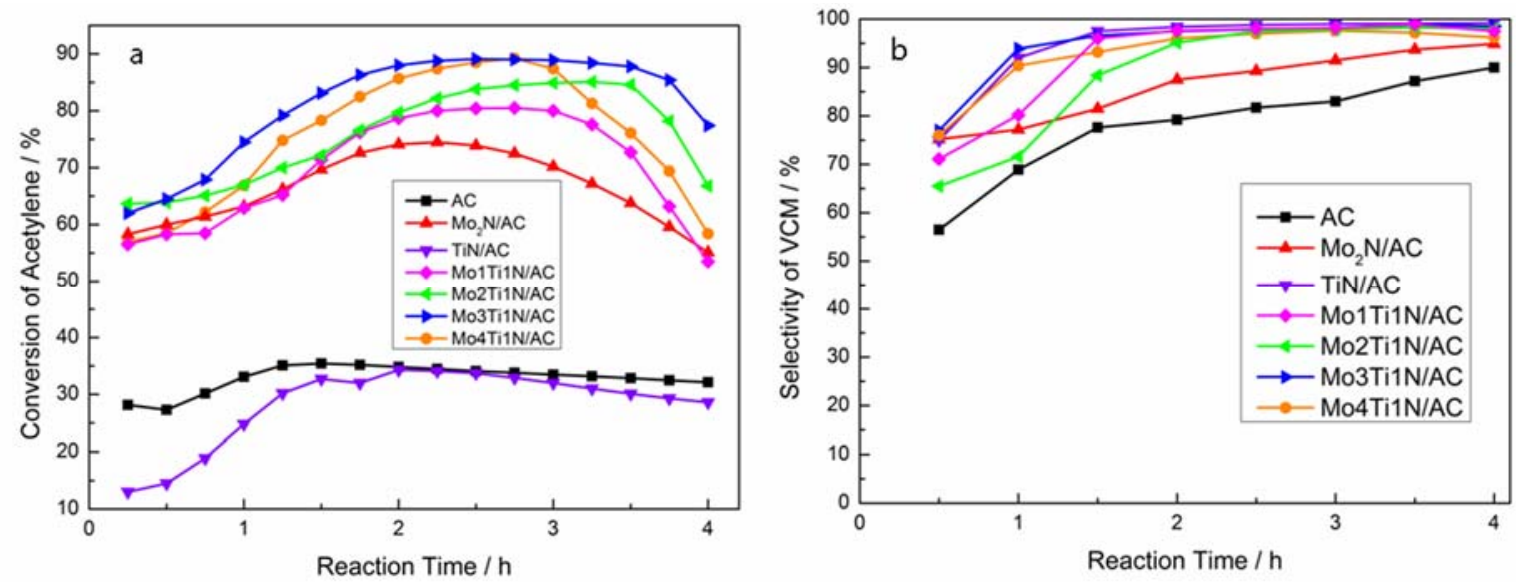

Figure 3. The (a) acetylene conversion and (b) VCM selectivity over catalysts of $\mathrm{AC}, \mathrm{TiN} / \mathrm{AC}$, $\mathrm{Mo}_{2} \mathrm{~N} / \mathrm{AC}, \mathrm{Mo}_{1} \mathrm{Ti}_{1} \mathrm{~N} / \mathrm{AC}, \mathrm{Mo}_{2} \mathrm{Ti}_{1} \mathrm{~N} / \mathrm{AC}, \mathrm{Mo}_{3} \mathrm{Ti}_{1} \mathrm{~N} / \mathrm{AC}, \mathrm{Mo}_{4} \mathrm{Ti}_{1} \mathrm{~N} / \mathrm{AC}$; Reaction conditions: Temperature $(T)=180{ }^{\circ} \mathrm{C}, \mathrm{C}_{2} \mathrm{H}_{2}(G H S V)=50 \mathrm{~h}^{-1}, V_{\mathrm{HCl}}: V_{\mathrm{C} 2 \mathrm{H} 2}=1.15: 1$. 


\subsection{Characteristics of Fresh and Used Samples}

To further study their physicochemical properties, we analyzed the pore structure of the TMNs and supports, as shown in Table 1, and the adsorption branches for the samples are shown in Figure S1. The carrier had the largest surface area and pore volume. After loading the ingredients, all parameters underwent a clear decrease, which means that an enormous degree of activation occurred in the channels and pores of the support; moreover, every sample exhibited a type IV nitrogen adsorption isotherm [34]. On comparing the two different TMNs, namely, the $\mathrm{Mo}_{2} \mathrm{~N} / \mathrm{AC}$ and TiN/AC catalysts, it is apparent that TiN/AC displayed an even larger pore structure in surface area, pore size, and volume. The pore volume and surface area increased along with the increase in the mole ratio of Mo:Ti. After the reaction had proceeded for $4 \mathrm{~h}$, TiN/AC underwent a slight decrease in surface area and pore volume, and the samples that contained Mo experienced a change in pore structure distinct from that in TiN/AC, with an especially dramatic loss of surface area and pore volume. This shows that the presence of Mo had a huge influence on the pore structure of the support. However, there was a slight difference in the used Mo-based catalysts, and the average pore diameter was higher than in the fresh BTMN catalysts. In contrast to Figure S1, this may indicate that a hysteresis loop that was formerly present disappeared for the Mo-based catalysts after the reaction. It was deduced that some coke deposits were possibly generated continuously throughout the entire reaction process, which led to a decrease in surface area and pore volume. As coke easily blocks micropores, after the reaction the mean diameter of the pores increased. As is widely known, in a porous support the active sites are mainly distributed on the surface, and thus a larger surface may possess more exposed active sites [34]. Furthermore, the capacity for reactant diffusion and product transfer largely depend on the pore structure and distribution; therefore, the change in pore structure may directly influence the stability of catalysts. This may also attribute to the rapid deactivation of the Mo-based catalysts.

The adsorption of reactants can influence the activity of a catalyst. To determine the adsorption capacity and activation of the reactants for different samples, TPD is always a useful method. Variations in the desorption temperature correspond to differences in binding or combination between the activated ingredient and the reactant; besides, the area of the desorption peak reflects the quantity of the adsorbed species. For the hydrochlorination reaction of acetylene, there was a focus on the ability of the catalysts to desorb acetylene and hydrogen chloride. Figure 4a shows the TPD profiles for the six samples of the desorption of $\mathrm{C}_{2} \mathrm{H}_{2}$. TiN/AC gave rise to very little adsorption of acetylene; in contrast, $\mathrm{Mo}_{2} \mathrm{~N} / \mathrm{AC}$ had the greatest adsorption ability among the samples based on the calculation of its peak area as presented in Table 2. For the BTMNs, the quantity of acetylene that was adsorbed decreased as the mole ratio of Mo and Ti increased. Furthermore, the desorption temperature of $\mathrm{Mo}_{3} \mathrm{Ti}_{1} \mathrm{~N} / \mathrm{AC}$ was the lowest at around $440{ }^{\circ} \mathrm{C}$ and adsorption was thus weak relative to that of other catalysts. Although TiN/AC had a low quantity of adsorbed acetylene, its desorption temperature was the highest, which suggested that the binding between the ingredient and acetylene was strong [35]. In this reaction, a higher degree of activation usually corresponds to stronger binding and a greater quantity of adsorbed $\mathrm{HCl}$. The peak area of $\mathrm{HCl}$ for TiN/AC was slightly greater than that for $\mathrm{Mo}_{2} \mathrm{~N} / \mathrm{AC}$, but it's desorption temperature was the lowest, which shows that $\mathrm{HCl}$ was hardly combined. When the elemental components were used together, the adsorption capacity for $\mathrm{HCl}$ immediately increased and was directly proportional to the mole ratio of Mo and Ti. However, there was also a slight difference between the four BTMNs catalysts, $\mathrm{Mo}_{3} \mathrm{Ti}_{1} \mathrm{~N} / \mathrm{AC}$ exhibited the strongest binding to $\mathrm{HCl}$ with a desorption temperature of nearly $272{ }^{\circ} \mathrm{C}$, as shown in Figure $4 \mathrm{~b}$. BTMNs had clearly different adsorption capability from TMNs; the results show clearly that BTMNs were not formed by simple addition of the single TMNs, but constituted new chemical products such as Mo-Ti-N or other form, in agreement with the TPD-MS analysis [36]. For two kinds of reactant, acetylene and $\mathrm{HCl}$, Mo-based catalysts exhibited completely different adsorption ability. This phenomenon can lead $\mathrm{C}_{2} \mathrm{H}_{2}$ to occupy the active site, whereas only a small amount of $\mathrm{HCl}$ can occupy this position and most of it has yet to participate in the reaction, and thus coke is easily produced on the surface of the catalysts. For this 
reaction, the capacity to adsorb $\mathrm{HCl}$ is the key that influences the activity and stability of catalysts [37]. This analysis also explained why the performance of $\mathrm{Mo}_{3} \mathrm{Ti}_{1} \mathrm{~N} / \mathrm{AC}$ was outstanding.
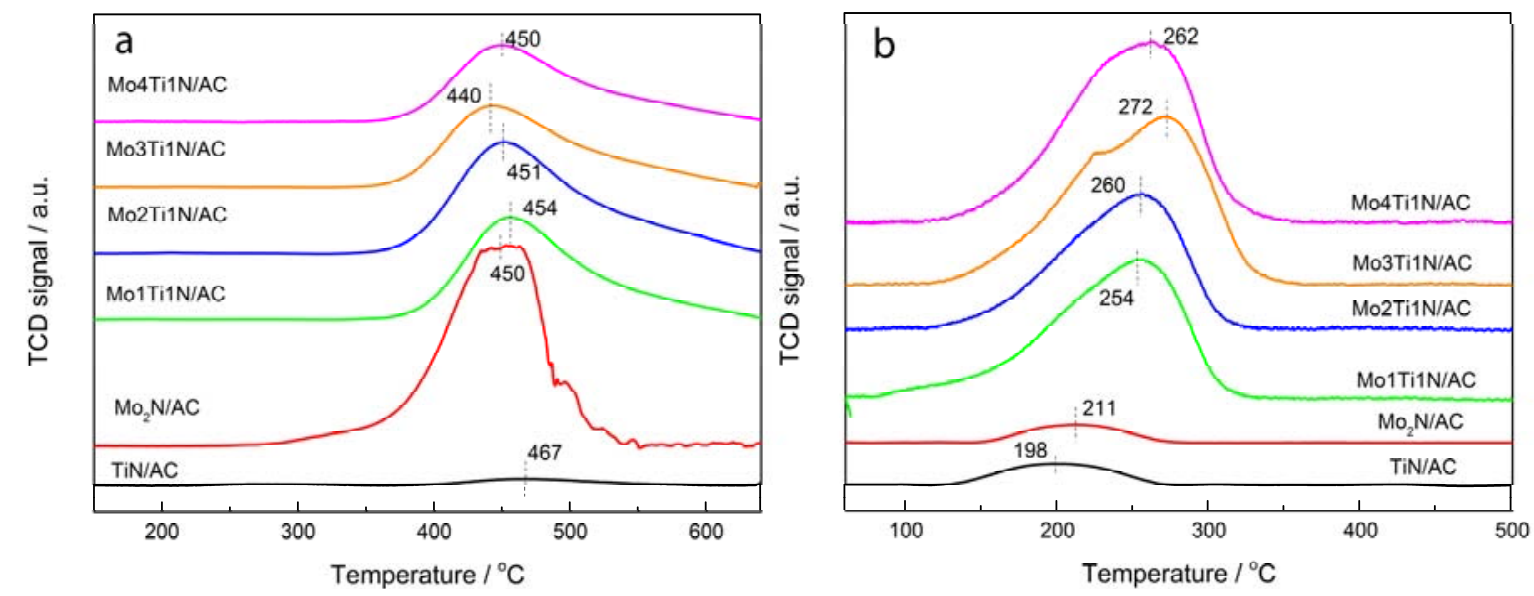

Figure 4. (a) $\mathrm{C}_{2} \mathrm{H}_{2}$-TPD and (b) $\mathrm{HCl}-\mathrm{TPD}$ analysis for catalysts.

Table 2. Calculation of peak area of different catalysts' desorption reactant.

\begin{tabular}{ccc}
\hline Samples & Peak Area of Desorption $\mathbf{C}_{\mathbf{2}} \mathbf{H}_{\mathbf{2}}$ & Peak Area of Desorption $\mathbf{H C l}$ \\
\hline $\mathrm{Mo}_{2} \mathrm{~N} / \mathrm{AC}$ & 12.6 & 0.06 \\
$\mathrm{TiN}_{\mathrm{AC}}$ & 0.57 & 0.10 \\
$\mathrm{Mo}_{1} \mathrm{Ti}_{1} \mathrm{~N} / \mathrm{AC}$ & 7.32 & 0.76 \\
$\mathrm{Mo}_{2} \mathrm{Ti}_{1} \mathrm{~N} / \mathrm{AC}$ & 6.95 & 0.90 \\
$\mathrm{Mo}_{3} \mathrm{Ti}_{1} \mathrm{~N} / \mathrm{AC}$ & 6.55 & 0.96 \\
$\mathrm{Mo}_{4} \mathrm{Ti}_{1} \mathrm{~N} / \mathrm{AC}$ & 6.08 & 0.99 \\
\hline
\end{tabular}

From their microscopic structure, differences in $\mathrm{TiN} / \mathrm{AC}, \mathrm{Mo}_{2} \mathrm{~N} / \mathrm{AC}$, and $\mathrm{Mo}_{3} \mathrm{Ti}_{1} \mathrm{~N} / \mathrm{AC}$ were investigated using TEM analysis, as shown in Figure 5. Figure 5a shows a TEM image of $\mathrm{Mo}_{2} \mathrm{~N} / \mathrm{AC}$ and its particle size distribution. It can be observed that $\mathrm{Mo}_{2} \mathrm{~N} / \mathrm{AC}$ nanoparticles form uniform spots on the surface of the carrier, and from calculations the average diameter of crystallites is about $1.35 \mathrm{~nm}$. An HR-TEM image of $\mathrm{Mo}_{2} \mathrm{~N} / \mathrm{AC}$ is present in Figure $5 \mathrm{~b}$, and by measuring its crystal lattice, an inter planar spacing can be obtained that corresponds to the (111) planes in $\mathrm{Mo}_{2} \mathrm{~N}$. Spherical TiN nanoparticles with an average particle size of $2.44 \mathrm{~nm}$ were observed in Figure $5 \mathrm{c}$. Their grains are larger than those of $\mathrm{Mo}_{2} \mathrm{~N} / \mathrm{AC}$. The lattice spacing of $0.25 \mathrm{~nm}$ and $0.22 \mathrm{~nm}$ shown in Figure $5 \mathrm{~d}$ are consistent with the (111) and (200) planes, respectively, of TiN [26]. In Figure 5e there can be observed some spherical structure and grain shape particles were combined together. The range of particle sizes extends from $0.5 \mathrm{~nm}$ to $5 \mathrm{~nm}$, but the average calculated value is in between, at only $2.22 \mathrm{~nm}$. From Figure $5 \mathrm{f}$ there can also be found different crystal phases that overlap together. This is evidence that BTMNs were formed from two different TMNs and shows both their advantages with well-dispersed nanoparticles of BTMNs [24]. Figure S2 shown the particles shape of three samples after the reaction. Compared with fresh catalysts, all the particles became a little bit larger than before. Used- $\mathrm{Mo}_{2} \mathrm{~N} / \mathrm{AC}$ show a large particle size distribution range from 0.5 to $3.5 \mathrm{~nm}$ and average grain diameter was $2.0 \mathrm{~nm}$. For the other two, used catalysts particles are found up to $6.5 \mathrm{~nm}$ in diameter, mean size is $2.9 \mathrm{~nm}$ over used-TiN/AC and $3.5 \mathrm{~nm}$ over used-Mo $\mathrm{Mo}_{3} \mathrm{Ti}_{1} \mathrm{~N} / \mathrm{AC}$, respectively. This phenomenon indicated that these catalysts are not resistant to sintering and also show aggregation or coke deposition during the reaction, this may be another reason for the deactivation. 

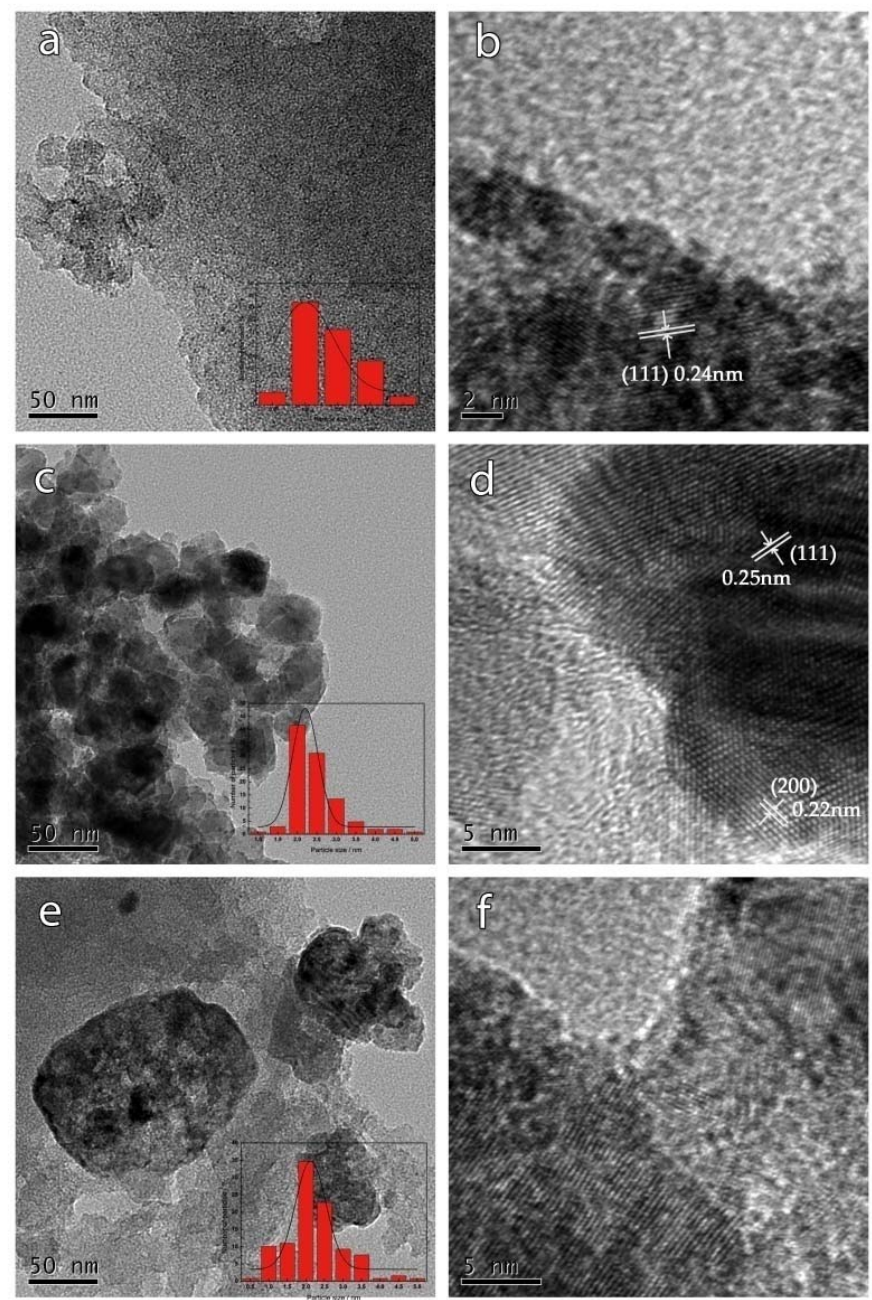

Figure 5. Representative TEM figures of $(\mathbf{a}, \mathbf{b}) \mathrm{Mo}_{2} \mathrm{~N} / \mathrm{AC} ;(\mathbf{c}, \mathbf{d}) \mathrm{TiN} / \mathrm{AC}$ and $(\mathbf{e}, \mathbf{f}) \mathrm{Mo}_{3} \mathrm{Ti}_{1} \mathrm{~N} / \mathrm{AC}$, respectively.

The elemental states of Mo, Ti, and N in the catalysts were analyzed by XPS. In the wide-scan spectrum shown in Figure S3, the peaks at 236, 284.8, 399.5, 458.6, and $531 \mathrm{eV}$ can be assigned to the binding energies of Mo 3d, C 1s, N 1s, Ti 2p, and O 1s, respectively. It can be concluded from the three contrasting plots that Mo and Ti coexisted in $\mathrm{Mo}_{3} \mathrm{Ti}_{1} \mathrm{~N} / \mathrm{AC}$. There was a Mo content of $4.39 \%$ in the $\mathrm{Mo}_{2} \mathrm{~N} / \mathrm{AC}$ catalyst, as shown by ICP analysis in Table S2. The content of Ti was $4.03 \%$ in TiN/AC, which showed that the two TMNs had nearly the same metal content. There are some very distinct differences between the $\mathrm{N}$ contents of the two TMNs listed in Table S1. In the carrier, the $\mathrm{N}$ content was only $0.09 \%$, and the $\mathrm{N}$ contents were $0.48 \%$ in TiN/AC and $1.73 \%$ in $\mathrm{Mo}_{2} \mathrm{~N} / \mathrm{AC}$; thereby, most $\mathrm{Ti}$ species present may not only be $\mathrm{TiN}$, in accordance with the former analysis, may easily form $\mathrm{TiO}_{2}$. $\mathrm{Mo}_{3} \mathrm{Ti}_{1} \mathrm{~N} / \mathrm{AC}$ consisted of $2.88 \% \mathrm{Mo}, 0.66 \% \mathrm{Ti}$, and $1.54 \% \mathrm{~N}$. In view of this, elemental contents of lower than $1 \%$ are hard to determine via XPS narrow-scan analysis (Figure S2). The XPS spectrum of Mo $3 \mathrm{~d}$ can be mainly deconvolved into two sub-peaks located at 229.7 and $232.9 \mathrm{eV}$, which is the $\mathrm{Mo}_{5 / 2}$ and $\mathrm{Mo}_{5} \mathrm{~d}_{3 / 2}$ valences corresponding $\mathrm{Mo}^{\delta+}(2<\delta<4)$ [38], $\mathrm{Mo}_{3} \mathrm{Ti}_{1} \mathrm{~N} / \mathrm{AC}$ and $\mathrm{Mo}_{2} \mathrm{~N} / \mathrm{AC}$ all have these two peaks. However, the Mo3d peak in the catalysts $\mathrm{Mo}_{3} \mathrm{TiN} / \mathrm{AC}$ exists differently as it was slightly shifted to higher binding energies with respect to $\mathrm{Mo}_{2} \mathrm{~N} / \mathrm{AC}$. Indicating that Mo atoms of the BTMN supplied electrons to Ti, leading to an increase in the extent of Ti d-band occupation near the Fermi level [26]. In the Ti 2p spectrum, we can observe three peaks at $464.3 \mathrm{eV}\left(\mathrm{TiO}_{2}\right), 460.5 \mathrm{eV}(\mathrm{TiN})$, and $458.5 \mathrm{eV}$ (Ti-O-N) [39] for TiN/AC (Table 3). XPS analysis can only determine the surface states of samples, which can explain why XRD analysis only detected a $\mathrm{TiO}_{2}$ peak for TiN/AC. This catalyst 
was easily oxidized in air to form a thin $\mathrm{TiO}_{2}$ film on the surface. However, Ti states can hardly be detected because of their low content in the sample of $\mathrm{Mo}_{3} \mathrm{Ti}_{1} \mathrm{~N} / \mathrm{AC}$. Therefore, we determined the $\mathrm{N}$ 1s peak energies for the samples. For $\mathrm{Mo}_{2} \mathrm{~N} / \mathrm{AC}$, the binding energy at $395.5 \mathrm{eV}$ corresponds to Mo-N bonds [38], and at the same time there still exist pyridinic-N and pyrrolic-N; however, Mo-N represents the largest amount of the three different forms of $\mathrm{N}$. For $\mathrm{Mo}_{3} \mathrm{Ti}_{1} \mathrm{~N} / \mathrm{AC}$, the $\mathrm{N} 1 \mathrm{~s}$ spectrum shows that Mo-N bonds ( $395.6 \mathrm{eV}$ ) form the predominant component and comprise $74.6 \%$ of the $\mathrm{N}$ content. The surplus $\mathrm{N}$ peaks belong to Ti-N bonds (397.1 eV) [26]. Taken together, from the results for the $\mathrm{N}$ content obtained by EA and XPS N 1s spectra the following conclusion can be drawn, namely, that $\mathrm{N}$ was present in the form of metal-N bonds.

Table 3. The binding energy and relative content of Mo, Ti and $\mathrm{N}$ species in the catalysts.

\begin{tabular}{cccccccccc}
\hline & \multicolumn{9}{c}{ Binding Energy/eV (Area/\%) } \\
\cline { 2 - 10 } Samples & \multicolumn{2}{c}{ Mo 3d } & \multicolumn{5}{c}{ Ti 2p } \\
& \cline { 2 - 10 } & $\mathbf{M o}^{\delta+}(2<\delta<4)$ & $\mathrm{TiO}_{2}$ & TiN & Ti-O-N & Pyridinic-N & Mo-N & Ti-N & Pyrrolic-N \\
\hline $\mathrm{Mo}_{2} \mathrm{~N} / \mathrm{AC}$ & $229.9(61.1)$ & $233.1(38.8)$ & - & - & - & $397.9(27.4)$ & $398.5(43.2)$ & $399.3(29.4)$ \\
\hline $\mathrm{TiN} / \mathrm{AC}$ & - & - & $464.3(29.0)$ & $460.5(11.5)$ & $458.5(59.5)$ & - & - & - & - \\
\hline $\mathrm{Mo}_{3} \mathrm{Ti}_{1} \mathrm{~N} / \mathrm{AC}$ & $229.9(54.5)$ & $233.1(45.4)$ & - & - & - & - & $398.6(76.4)$ & $397.1(23.6)$ & - \\
\hline
\end{tabular}

There are still unresolved issues, namely, the large decline in the pore structure after the reaction. Figure S4 shows the results of thermogravimetric analysis used for testing the deposition of carbon on the catalysts via a temperature-programmed route in air to test how the quality of the catalysts changed before and after the reaction to deduce how much coke was generated during the reaction. The quality declined below $110{ }^{\circ} \mathrm{C}$ as the carrier adsorbed moisture from the air. Another significant decline in quality was observed at high temperatures, which supported combustion in air [34]. Therefore, the range over which coke was removed was higher than $110^{\circ} \mathrm{C}$ and lower than the combustion temperature. Table 4 summarizes the contents of carbon deposited on the six samples. On comparing the coke contents of the two TMN catalysts, the coke content of $\mathrm{Mo}_{2} \mathrm{~N} / \mathrm{AC}$ significantly exceeded that of TiN/AC. TiN/AC also had the lowest content of all the samples and its pore structure changed to the least extent after the reaction, which was confirmed by BET analysis. For the BTMN catalysts, it is obvious that the order of the coke content was as follows: $\mathrm{Mo}_{3} \mathrm{Ti}_{1} \mathrm{~N} / \mathrm{AC}(9.2 \%)<\mathrm{Mo}_{2} \mathrm{Ti}_{1} \mathrm{~N} / \mathrm{AC}(9.3 \%)$ $<\mathrm{Mo}_{1} \mathrm{Ti}_{1} \mathrm{~N} / \mathrm{AC}(10.9 \%)<\mathrm{Mo}_{4} \mathrm{Ti}_{1} \mathrm{~N} / \mathrm{AC}(11.8 \%)$. It is indicated that the Mo-based catalysts easily produced large amounts of coke during the reaction, which was connected with the change in pore quantity between the fresh and used catalysts. There existed a connection between the desorption area and the attributes of $\mathrm{C}_{2} \mathrm{H}_{2}$. For Mo-based catalysts the adsorption of $\mathrm{C}_{2} \mathrm{H}_{2}$ was easy and desorption was harder during the reaction, and much more $\mathrm{C}_{2} \mathrm{H}_{2}$ occupied the activated site, which led to the generation of large amounts of coke, which thereby blocked the pore structure. Upon the huge decline in the surface area of the catalyst, much more activated ingredients were blocked in the pores by the deposition of coke and could hardly come into contact with the reactant, which also influenced the mass transfer of the catalyst and thereby directly caused a decline in conversion.

Table 4. The carbon depositions of the three catalysts.

\begin{tabular}{cc}
\hline Catalyst & Amount of Carbon Deposition (\%) \\
\hline $\mathrm{Mo}_{2} \mathrm{~N} / \mathrm{AC}$ & 6.63 \\
$\mathrm{TiN}_{\mathrm{AC}}$ & 1.88 \\
$\mathrm{Mo}_{1} \mathrm{Ti}_{1} \mathrm{~N} / \mathrm{AC}$ & 10.9 \\
$\mathrm{Mo}_{2} \mathrm{Ti}_{1} \mathrm{~N} / \mathrm{AC}$ & 9.3 \\
$\mathrm{Mo}_{3} \mathrm{Ti}_{1} \mathrm{~N} / \mathrm{AC}$ & 9.2 \\
$\mathrm{Mo}_{4} \mathrm{Ti}_{1} \mathrm{~N} / \mathrm{AC}$ & 11.8 \\
\hline
\end{tabular}




\section{Conclusions}

BTMNs are inexpensive, easy to produce, and lead to no pollution to the environment, when used as novel catalysts first employed for the hydrochlorination reaction of acetylene. The optimal mole ratio of $\mathrm{Mo} / \mathrm{Ti}$ was $3: 1$, whereas the conversion of acetylene reached $89 \%$, and the selectivity for VCM attained $98.5 \%$. The experimental data indicated that the doping of Ti in Mo-based catalysts reduced the adsorption of acetylene and also increased the adsorption capacity for hydrogen chloride. This also contributed to the unique structure of BTMNs. However, their stability was poor, owing to the main deactivating factors of the difficulty in desorbing $\mathrm{C}_{2} \mathrm{H}_{2}$, catalysts active ingredient are not resistant to sintering easy to aggregation and the production of large amounts of coke deposits under the reaction conditions used in this study. The content of adsorbed $\mathrm{C}_{2} \mathrm{H}_{2}$ can determine the production of coke. If the catalyst possesses a lower desorption temperature for acetylene and a higher desorption temperature for $\mathrm{HCl}$, this indicates that it may have a greater degree of activation.

Most importantly, $\mathrm{Mo}_{3} \mathrm{Ti}_{1} \mathrm{~N} / \mathrm{AC}$ exhibited much greater activity than any other TMN catalysts. This catalyst may be used in the design of a novel catalyst system for a wide range of applications in the synthesis process of VCM.

Supplementary Materials: The following are available online at www.mdpi.com/2073-4344/7/7/200/s1, Figure S1: The $\mathrm{N}_{2}$ adsorption-desorption isotherms for (a) fresh and (b) spend catalysts, Figure S2: Representative TEM figures of (a) used-Mo $2 \mathrm{~N} / \mathrm{AC}$; (b) used-TiN/AC and (c) used-Mo 3 Ti1N/AC, respectively, Figure S3: XPS spectra of $\mathrm{Mo}_{2} \mathrm{~N} / \mathrm{AC}$, TiN/AC and $\mathrm{Mo}_{3}$ Ti1N/AC, Figure S4: TG-DTG curves of six different catalysts: (a) $\mathrm{Mo}_{2} \mathrm{~N} / \mathrm{AC}$; (b) TiN/AC; (c) Mo $\mathrm{Ti}_{1} \mathrm{~N} / \mathrm{AC}$; (d) Mo $\mathrm{Mo}_{2} \mathrm{Ti} 1 \mathrm{~N} / \mathrm{AC}$; (e) Mo $\mathrm{O}_{3} \mathrm{Ti1N} / \mathrm{AC}$ and (f) Mo $\mathrm{o}_{4} \mathrm{Ti1N} / \mathrm{AC}$, Table S1: $\mathrm{N}$ contents in catalysts analysis by EA, Table S2: Metal elements content in samples investigate by ICP.

Acknowledgments: The authors are grateful for the financial support from National Natural Science Funds of China (NSFC, U1403294, 21666033), and young scientific and technological innovation leader of Bingtuan (2015BC001).

Author Contributions: As for authors, Hui Dai completed the main experiments, also finished the manuscript with direction from Mingyuan Zhu; Haiyang Zhang and Feng Yu was responsible for analyzed the data; Chao Wang provided help with experiment. Bin Dai was corresponding authors in charge of supervising the work.

Conflicts of Interest: The authors declare no conflict of interest.

\section{References}

1. Zhu, M.; Wang, Q.; Chen, K.; Wang, Y.; Huang, C.; Dai, H.; Yu, F.; Kang, L.; Dai, B. Development of a heterogeneous non-mercury catalyst for acetylene hydrochlorination. ACS Catal. 2015, 5, 5306-5316. [CrossRef]

2. Zhang, J.; Liu, N.; Li, W.; Dai, B. Progress on cleaner production of vinyl chloride monomers over non-mercury catalysts. Front. Chem. Sci. Eng. 2011, 5, 514-520. [CrossRef]

3. Dai, B.; Wang, Q.; Yu, F.; Zhu, M. Effect of au nano-particle aggregation on the deactivation of the AUCL3/ac catalyst for acetylene hydrochlorination. Sci. Rep. 2014, 5, 10553. [CrossRef] [PubMed]

4. Zhang, H.; Dai, B.; Wang, X.; Xu, L.; Zhu, M. Hydrochlorination of acetylene to vinyl chloride monomer over bimetallic au-la/sac catalysts. J. Ind. Eng. Chem. 2012, 18, 49-54. [CrossRef]

5. Zhang, H.; Dai, B.; Wang, X.; Li, W.; Han, Y.; Gu, J.; Zhang, J. Non-mercury catalytic acetylene hydrochlorination over bimetallic $\mathrm{Au}-\mathrm{Co}(\mathrm{iii}) / \mathrm{sac}$ catalysts for vinyl chloride monomer production. Green Chem. 2013, 15, 829-836. [CrossRef]

6. Conte, M.; Carley, A.F.; Attard, G.; Herzing, A.A.; Kiely, C.J.; Hutchings, G.J. Hydrochlorination of acetylene using supported bimetallic au-based catalysts. J. Catal. 2008, 257, 190-198. [CrossRef]

7. Nkosi, B.; Adams, M.D.; Coville, N.J.; Hutchings, G.J. Hydrochlorination of acetylene using carbon-supported gold catalysts: A study of catalyst reactivation. J. Catal. 1991, 128, 378-386. [CrossRef]

8. Zhang, J.; Sheng, W.; Guo, C.; Li, W. Acetylene hydrochlorination over bimetallic ru-based catalysts. RSC Adv. 2013, 3, 21062-21068. [CrossRef]

9. Li, G.; Li, W.; Zhang, H.; Pu, Y.; Sun, M.; Zhang, J. Non-mercury catalytic acetylene hydrochlorination over ru catalysts enhanced by carbon nanotubes. RSC Adv. 2015, 5, 9002-9008. [CrossRef] 
10. Pu, Y.; Zhang, J.; Wang, X.; Zhang, H.; Yu, L.; Dong, Y.; Li, W. Bimetallic Au-Ni/CsS catalysts for acetylene hydrochlorination. Catal. Sci. Technol. 2014, 4, 4426-4432. [CrossRef]

11. Zhao, J.; Zeng, J.; Cheng, X.; Wang, L.; Yang, H.; Shen, B. An au-cu bimetal catalyst for acetylene hydrochlorination with renewable $\gamma-\mathrm{Al}_{2} \mathrm{O}_{3}$ as the support. RSC Adv. 2015, 5, 16727-16734. [CrossRef]

12. Zhao, J.; Zhang, T.; Di, X.; Xu, J.; Xu, J.; Feng, F.; Jun, N.; Li, X. Nitrogen-modified activated carbon supported bimetallic gold-cesium (i) as highly active and stable catalyst for the hydrochlorination of acetylene. RSC Adv. 2015, 5, 6925-6931. [CrossRef]

13. Wang, B.; Yu, L.; Zhang, J.; Pu, Y.; Zhang, H.; Li, W. Phosphorus-doped carbon supports enhance gold-based catalysts for acetylene hydrochlorination. RSC Adv. 2014, 4, 15877-15885. [CrossRef]

14. Wang, X.; Zhu, M.; Zhang, H.; Chen, K.; Wang, Q.; Li, X. Melamine modification of spherical activated carbon and its effects on acetylene hydrochlorination. J. Wuhan Univ. Technol. Mater. Sci. Ed. 2014, 29, 1147-1151.

15. Li, X.; Zhu, M.; Dai, B. AuCl3 on polypyrrole-modified carbon nanotubes as acetylene hydrochlorination catalysts. Appl. Catal. B Environ. 2013, 142, 234-240. [CrossRef]

16. Dai, B.; Chen, K.; Wang, Y.; Kang, L.; Zhu, M. Boron and nitrogen doping in graphene for the catalysis of acetylene hydrochlorination. ACS Catal. 2015, 5, 2541-2547. [CrossRef]

17. Li, X.; Yu, L.; Ren, P.; Wu, X.; Sun, L.; Jiao, F.; Bao, X. Silicon carbide-derived carbon nanocomposite as a substitute for mercury in the catalytic hydrochlorination of acetylene. Nat. Commun. 2014, 5, 3688-3694. [CrossRef] [PubMed]

18. Dai, B.; Zhao, W.; Zhu, M. The preparation of Cu-g- $\mathrm{C}_{3} \mathrm{~N}_{4} / \mathrm{AC}$ catalyst for acetylene hydrochlorination. Catalysts 2016, 6, 193.

19. Toth, L. Transition Metal Carbides and Nitrides; Elsevier: New York, NY, USA, 1971.

20. Alhajri, N.S.; Anjum, D.H.; Hedhili, M.N.; Takanabe, K. Generation and characteristics of iv-vi transition metal nitride and carbide nanoparticles using a reactive mesoporous carbon nitride. ChemistrySelect 2016, 1, 290-296. [CrossRef]

21. Ham, D.J.; Lee, J.S. Transition metal carbides and nitrides as electrode materials for low temperature fuel cells. Energies 2009, 2, 873-899. [CrossRef]

22. Chen, W.-F.; Muckerman, J.T.; Fujita, E. Recent developments in transition metal carbides and nitrides as hydrogen evolution electrocatalysts. Chem. Commun. 2013, 49, 8896-8909. [CrossRef] [PubMed]

23. Pan, Z.; Xiao, Y.; Fu, Z.; Zhan, G.; Wu, S.; Xiao, C.; Hu, G.; Wei, Z. Hollow and porous titanium nitride nanotubes as high-performance catalyst supports for oxygen reduction reaction. J. Mater. Chem. A 2014, 2, 13966-13975. [CrossRef]

24. Xiao, Y.; Fu, Z.; Zhan, G.; Pan, Z.; Xiao, C.; Wu, S.; Chen, C.; Hu, G.; Wei, Z. Increasing pt methanol oxidation reaction activity and durability with a titanium molybdenum nitride catalyst support. J. Power Sources 2015, 273, 33-40. [CrossRef]

25. Wang, L.; Sun, J.; Song, R.; Yang, S.; Song, H. Hybrid 2D-0D Graphene-VR Quantum Dots for Superior Lithium and Sodium Storage. Adv. Energy Mater. 2015, 6, 1502067. [CrossRef]

26. Tian, X.; Luo, J.; Nan, H.; Fu, Z.; Zeng, J.; Liao, S. Binary transition metal nitrides with enhanced activity and durability for the oxygen reduction reaction. J. Mater. Chem. A 2015, 3, 16801-16809. [CrossRef]

27. Cao, B.; Veith, G.M.; Neuefeind, J.C.; Adzic, R.R.; Khalifah, P.G. Mixed close-packed cobalt molybdenum nitrides as non-noble metal electrocatalysts for the hydrogen evolution reaction. J. Am. Chem. Soc. 2013, 51, 19186-19192. [CrossRef] [PubMed]

28. Yang, Z.; Guo, S.; Pan, X.; Wang, J.; Bao, X. Fen nanoparticles confined in carbon nanotubes for co hydrogenation. Energy Environ. Sci. 2011, 4, 4500-4503. [CrossRef]

29. Podila, S.; Zaman, S.F.; Driss, H.; Alhamed, Y.A.; Al-Zahrani, A.A.; Petrova, L.A. Hydrogen production by ammonia decomposition using high surface area $\mathrm{Mo}_{2} \mathrm{~N}$ and $\mathrm{Co}_{3} \mathrm{Mo}_{3} \mathrm{~N}$ catalysts. Catal. Sci. Technol. 2013, 6, 1496-1506. [CrossRef]

30. Gao, Q.; Wang, S.; Ma, Y.; Tang, Y.; Giordano, C.; Antonietti, M. $\mathrm{SiO}_{2}$-surface-assisted controllable synthesis of taon and Ta3N5 nanoparticles for alkene epoxidation. Angew. Chem. 2012, 124, 985-989. [CrossRef]

31. Klug, H.P.; Alexander, L.E. X-ray Diffraction Procedures; Wiley: New York, NY, USA, 1954; Volume 2.

32. Tian, X.; Luom, J.; Nan, H.; Zou, H.; Chen, R.; Shu, T.; Li, X.; Li, Y.; Song, H.; Liao, S.; et al. Transition metal nitride coated with atomic layers of $\mathrm{pt}$ as a low-cost, highly stable electrocatalyst for the oxygen reduction reaction. J. Am. Chem. Soc. 2016, 138, 1575-1583. [CrossRef] [PubMed] 
33. Shi, C.; Zhu, A.; Yang, X.; Au, C. On the catalytic nature of vn, $\mathrm{Mo}_{2} \mathrm{~N}$, and $\mathrm{W}_{2} \mathrm{~N}$ nitrides for $\mathrm{NO}$ reduction with hydrogen. Appl. Catal. A Gen. 2004, 276, 223-230. [CrossRef]

34. Chen, K.; Kang, L.; Zhu, M.; Dai, B. Mesoporous carbon with controllable pore sizes as a support of the $\mathrm{AuCl} 3$ catalyst for acetylene hydrochlorination. Catal. Sci. Technol. 2014, 5, 1035-1040. [CrossRef]

35. Zhao, J.; Xu, J.; Xu, J.; Ni, J.; Zhang, T.; Xu, X.; Li, X. Activated-carbon-supported gold-cesium(i) as highly effective catalysts for hydrochlorination of acetylene to vinyl chloride. ChemPlusChem 2015, 80, $196-201$. [CrossRef]

36. Zhao, J.; Zhang, T.; Di, X.; Xu, J.; Gu, S.; Zhang, Q.; Ni, J.; Li, X. Activated carbon supported ternary gold-cesium(i)-indium(iii) catalyst for the hydrochlorination of acetylene. Catal. Sci. Technol. 2015, 5, 4973-4984. [CrossRef]

37. Zhang, J.; He, Z.; Li, W.; Han, Y. Deactivation mechanism of AuCl3 catalyst in acetylene hydrochlorination reaction: A dft study. Rsc Adv. 2012, 2, 4814-4821. [CrossRef]

38. Morozan, A.; Goellner, V.; Zitolo, A.; Fonda, E.; Donnadieu, B.; Jonesa, D.; Jaouen, F. Synergy between molybdenum nitride and gold leading to platinum-like activity for hydrogen evolution. Phys. Chem. Chem. Phys. 2015, 17, 4047-4053. [CrossRef] [PubMed]

39. Zhan, G.; Fu, Z.; Sun, D.; Pan, Z.; Xiao, C.; Wu, S.; Chen, C.; Hu, G.; Wei, Z. Platinum nanoparticles decorated robust binary transition metal nitrideecarbon nanotubes hybrid as an efficient electrocatalyst for the methanol oxidation reaction. J. Power Sources 2016, 326, 84-92. [CrossRef]

(C) 2017 by the authors. Licensee MDPI, Basel, Switzerland. This article is an open access article distributed under the terms and conditions of the Creative Commons Attribution (CC BY) license (http:/ / creativecommons.org/licenses/by/4.0/). 